03.1;05.1

\title{
Исследование взаимного влияния группы ударников при высокоскоростном одновременном входе в воду
}

\author{
(C) А.Н. Ищенко, С.А. Афранасьева ", В.В. Буркин, А.С. Дьячковский, А.В. Чупашев \\ Научно-исследовательский институт прикладной математики и механики \\ Национального исследовательского Томского государственного университета, \\ Томск, Россия \\ ฯ E-mail: s.a.afanasyeva@mail.ru
}

Поступило в Редакцию 26 июня 2019г.

В окончательной редакции 26 июня 2019г.

Принято к публикации 5 июля 2019г.

\begin{abstract}
Проведено экспериментальное исследование высокоскоростного движения группы суперкавитирующих кинетических ударников при одновременном входе в воду. Разработана экспериментальная методика метания и исследования высокоскоростного движения суперкавитирующих ударников в условиях гидробаллистического стенда. Получены экспериментальные данные о движении двух идентичных суперкавитирующих ударников на начальном участке траектории при скоростях порядка $1100 \mathrm{~m} / \mathrm{s}$, которые демонстрируют возможность устойчивого движения группы суперкавитирующих ударников в воде и достижения ими подводной цели.
\end{abstract}

Ключевые слова: вода, суперкавитирующий ударник, групповое метание.

DOI: 10.21883/PJTF.2019.20.48395.17950

В настоящее время проводятся интенсивные комплексные исследования по разработке научных основ, возможностей применения, а также параметров функционирования в воде перспективных образцов подводных суперкавитирующих ударников кинетического действия, в частности связанных с сохранностью ударника и точностью его попадания в зону прицеливания. В литературе имеется немало данных по каждой проблеме из этого комплекса: придание высокой начальной скорости, преодоление сопротивления воды и обеспечение устойчивого движения. При больших скоростях движение в воде наиболее эффективно в режиме суперкавитации, когда за лицевой поверхностью головной части ударника (кавитатором) образуется каверна, полностью охватывающая тело [1-3]. При этом на движущуюся модель действует только сила сопротивления на кавитаторе. Однако в этом режиме высокоскоростному прониканию сопутствует область высокого давления, которая сосредоточена в районе головной части ударника и может вызвать пластическую деформацию и даже его разрушение [4], что усугубляет проблему устойчивости движения и существенно повышает требования к прочностным характеристикам материала для изготовления ударника.

В настоящей работе предлагается повысить эффективность функционирования суперкавитирующих ударников кинетического действия путем увеличения количества ударников, стартующих одновременно из одной баллистической установки (с учетом перечисленных выше факторов). Движение в воде при пушечном старте группы суперкавитирующих ударников к настоящему времени изучено недостаточно и представляет значительный научный, а также практический интерес.
На базе разработанного гидробаллистического комплекса [5] проведены исследования высокоскоростного движения в воде суперкавитирующих кинетических ударников при групповом пушечном старте. Гидробаллистическая трасса имеет протяженность водного участка, заканчивающегося мишенным блоком, $10.5 \mathrm{~m}$. Вдоль траектории движения ударников установлены три рамы-мишени из полимерной пленки на расстоянии 0.7, 2.4 и $6.7 \mathrm{~m}$ соответственно. Для видеорегистрации в иллюминаторе на расстоянии $3.2 \mathrm{~m}$ установлена видеорегистрирующая аппаратура.

Для выстрела из гладкоствольной баллистической установки ударники помещаются в ведущее устройство с толкающим поддоном. На рис. 1 приведена фотография метаемой сборки с двумя ударниками.

Расстояние между осями ударников составляет $13 \mathrm{~mm}$. Каждый ударник представляет собой тонкий усеченный конус массой $m=55 \mathrm{~g}$ и длиной $l=100 \mathrm{~mm}$. Диаметр дискового кавитатора составлял $d_{c}=2 \mathrm{~mm}$, диаметр основания ударника $d_{b}=9 \mathrm{~mm}$. Ударники изготовлены из высокопрочного сплава ВНЖ-95. На боковую поверхность ударников маркером нанесены масштабные линии, позволяющие идентифицировать их на кадрах высокоскоростной видеорегистрации. Сборка в ускорителе помещается таким образом, чтобы ударники располагались вертикально относительно друг друга, что повышает информативность изображений на видеорегистраторе.

Рассмотрим результаты эксперимента при дульной скорости $V_{m}=1087 \mathrm{~m} / \mathrm{s}$ (рис. 2 и 3). На воздушном участке траектории (рис. 2,a) перед входом в воду наблюдается освобождение параллельно движущихся ударников от ведущего устройства. На рис. $2, b$ и с приведены фотографии, иллюстрирующие устойчивое движение обоих суперкавитирующих ударников на расстоянии 


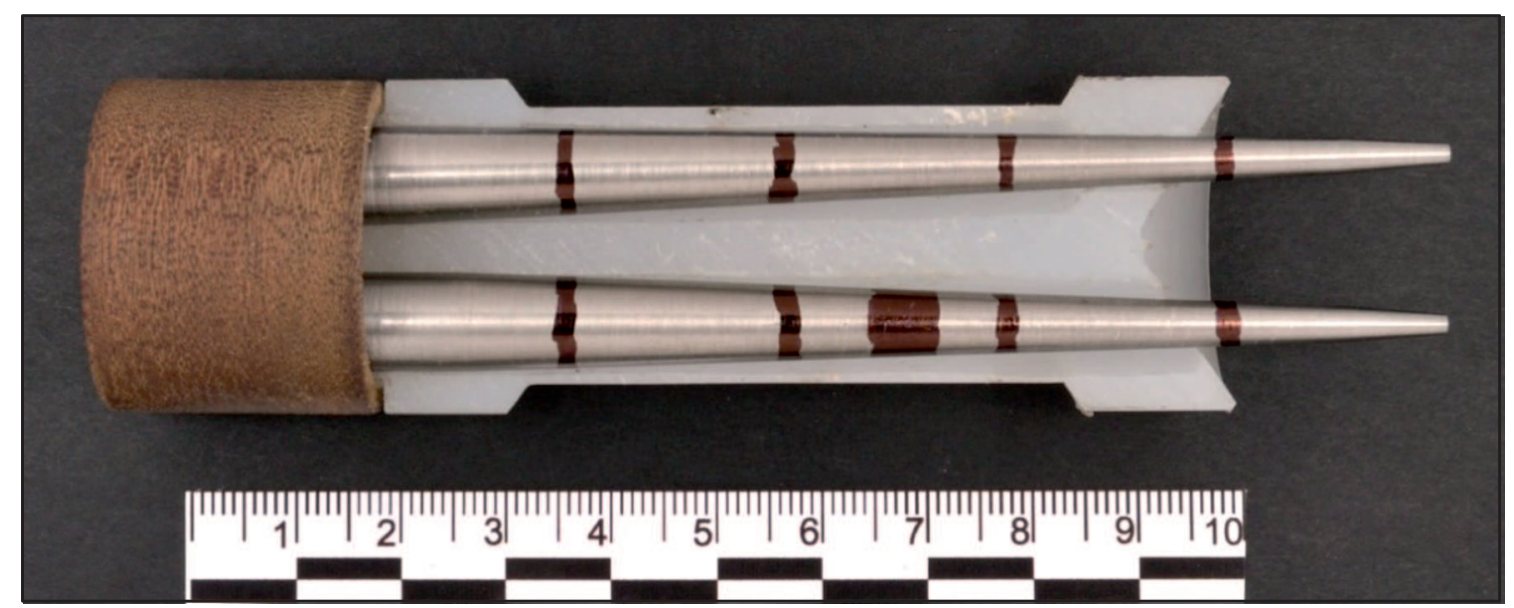

Рис. 1. Вид ударников в метаемой сборке.
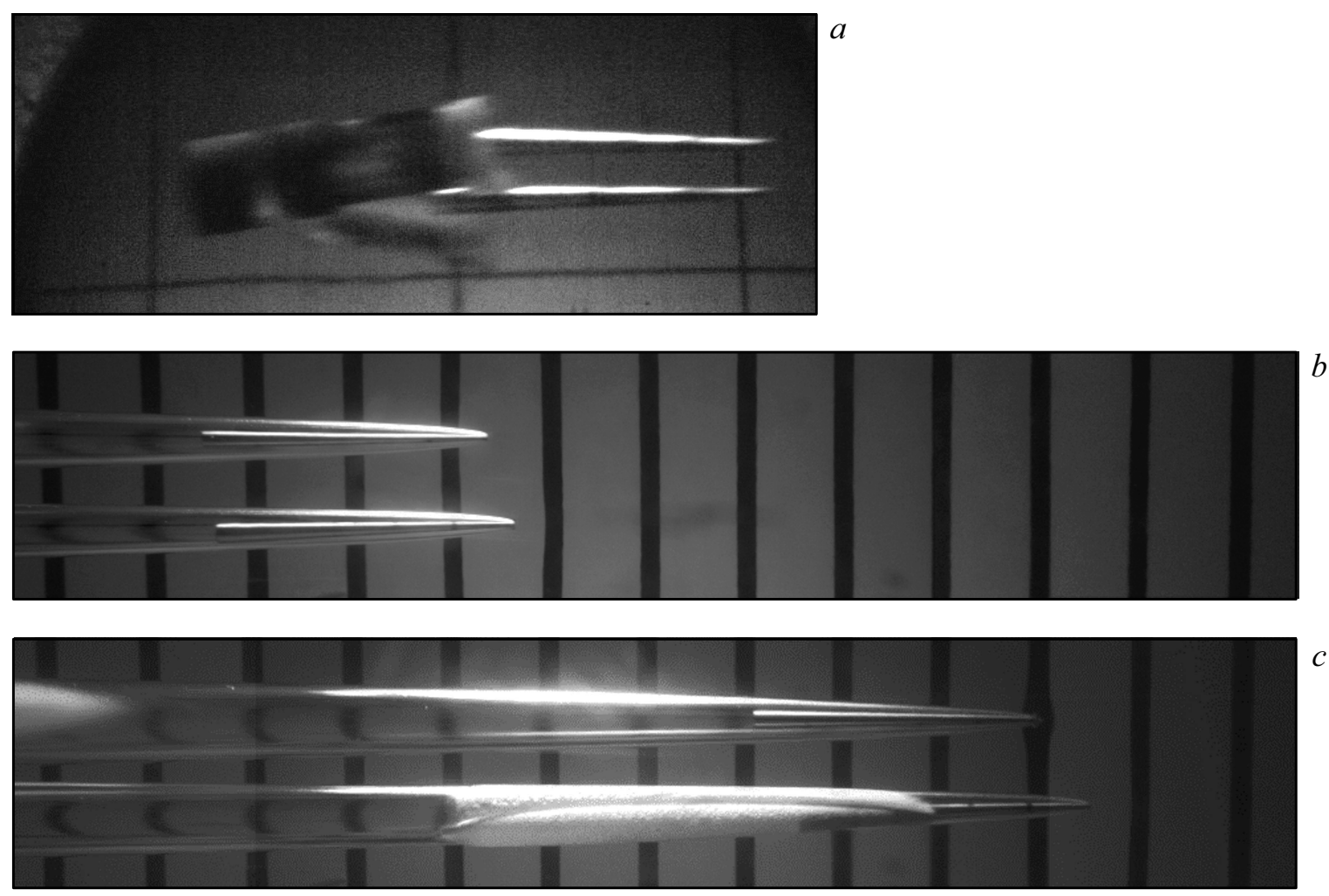

Рис. 2. Фоторегистограмма группового движения суперкавитирующих кинетических ударников в воздухе $(a)$ и в воде $(b, c)$.

$3.2 \mathrm{~m}$ от входа в воду в промежутке времени $0.2 \mathrm{~ms}$. На рис. 2, c запечатлено, как ударник основанием задевает внутреннюю поверхность каверны - глиссирует. Это является стабилизирующим фактором движения ударника в случае возникновения возмущений [4]. Преодолев водный участок трассы длиной $10.5 \mathrm{~m}$, ударники пробили стальную плиту толщиной $6 \mathrm{~mm}$.

На рис. 3, а показаны точка прицеливания (крест) и два отверстия от пробивших мишень ударников. На рис. 3, $b$ приведены траектории движения в воде двух суперкавитирующих ударников, построенные по отмет- кам на рамах-мишенях и подводной преграде: линиями показаны траектории, а точками - проекции траекторий ударников на координатные плоскости. На первой раме-мишени расстояние между ударниками соответствует их первоначальному расположению в метаемой сборке. Позже ударники расходятся относительно друг друга в телесном угле $\varphi=3.8^{\circ}$ : на второй раме-мишени расстояние между осями ударников составляет $35 \mathrm{~mm}$; на третьей раме-мишени — $58 \mathrm{~mm}$. В конце трассы, судя по отверстиям в пробитой преграде, расстояние между осями ударников составляет $65 \mathrm{~mm}$. На этом 


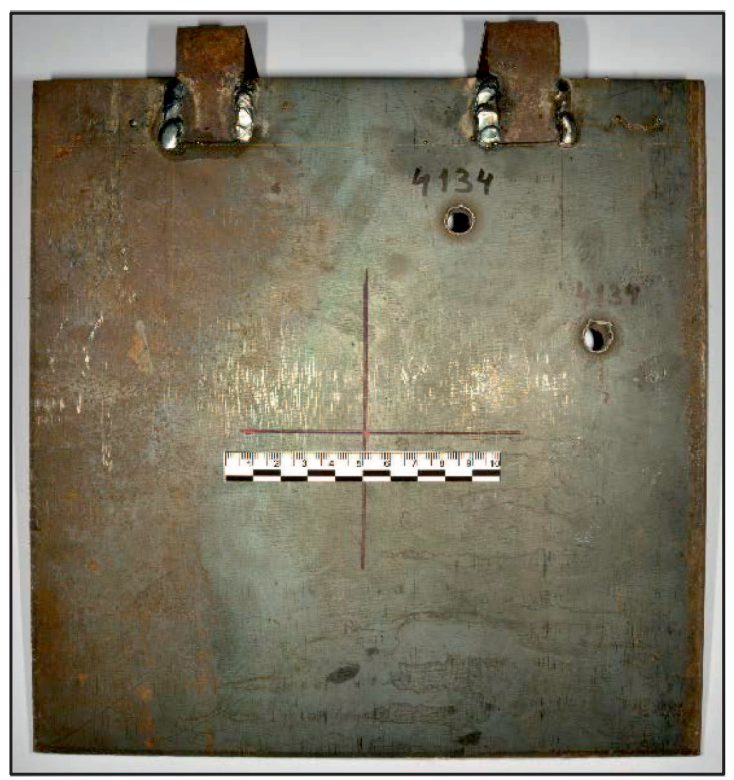

$a$

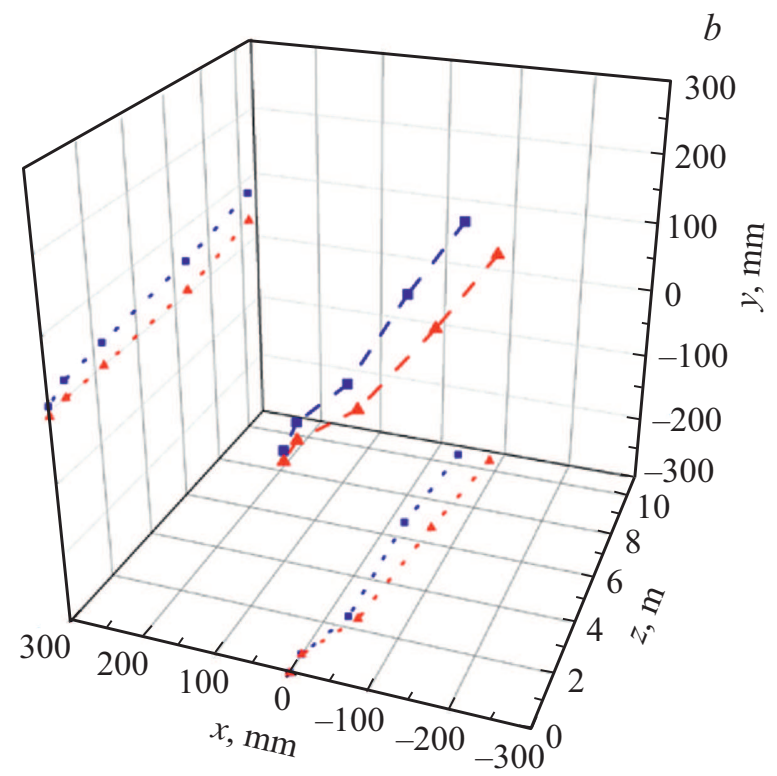

Рис. 3. Вид пробитой двумя ударниками мишени $(a)$ и траектории их движения в воде $(b)$. Квадраты - верхний ударник, треугольники - нижний ударник.

участке трассы ударники дополнительно расходятся на $\varphi=0.018^{\circ}$, т.е. практически взаимное влияние ударников друг на друга сведено к минимуму.

Для выявления особенностей взаимодействия группы суперкавитирующих ударников в воде проведено численное моделирование входа в воду двух ударников в рамках предложенной в [6] математической модели в полной пространственной постановке. В начале движения формируется общая для обоих ударников волна сжатия в области головной части $(\sim 0.0187 \mathrm{GPa})$, затем зона повышенного давления между кавернами ударников перемещается к кормовой части $(\sim 0.0175 \mathrm{GPa})$. Со временем давление в среде между ударниками ослабевает $(\sim 0.0025 \mathrm{GPa})$. За время действия повышенного давления формируется боковое усилие, которое и раздвигает ударники.

Для оценки действия исследуемых ударников на подводную преграду на различных расстояниях $L$ определены скорость встречи $V_{0}$ по формуле

$$
V_{0}=\exp \left(\ln V_{m}-L k\right)
$$

(где $k=\rho C_{x} S_{c} / 2 m, C_{x}=0.82(1+\sigma), \rho-$ плотность воды, $\sigma$ - число кавитации, $S_{c}$ - площадь кавитатора) и толщина пробиваемой преграды из стали $b_{\mathrm{Fe}}$ и алюминия $b_{\mathrm{Al}}$ по эмпирической формуле Жакоба де-Марра при встрече „в нормаль“

$$
b=\frac{m^{0.75}}{d_{b}^{1.07}}\left(\frac{V_{0}}{K}\right)^{1.43}
$$

где $b$ - толщина пробиваемой преграды $(\mathrm{dm}), V_{0}-$ скорость встречи с преградой $(\mathrm{m} / \mathrm{s}), d_{b}$ - диаметр основания ударника $(\mathrm{dm}), m-$ масса ударника $(\mathrm{kg})$,
Параметры взаимодействия ударника с преградой

\begin{tabular}{c|c|c|c|c|c}
\hline \multicolumn{3}{c|}{$L=60 \mathrm{~m}$} & \multicolumn{3}{c}{$L=100 \mathrm{~m}$} \\
\hline$V_{0}, \mathrm{~m} / \mathrm{s}$ & $b_{\mathrm{Fe}}, \mathrm{mm}$ & $b_{\mathrm{Al}}, \mathrm{mm}$ & $V_{0}, \mathrm{~m} / \mathrm{s}$ & $b_{\mathrm{Fe}}, \mathrm{mm}$ & $b_{\mathrm{Al}}, \mathrm{mm}$ \\
\hline 251 & 6 & 12 & 95 & 3 & 7
\end{tabular}

$K$ - коэффициент, характеризующий свойства материала преграды (для алюминиевого сплава АМГ $K=1500$, для стали $K=2500)$.

В таблице приведены данные по взаимодействию ударника с преградой на расстояниях 60 и $100 \mathrm{~m}$ в воде при дульной скорости ударников $V_{m}=1100 \mathrm{~m} / \mathrm{s}$. Судя по данным расчета, на указанных расстояниях от точки выстрела ударники имеют достаточную скорость для пробития преград из стали $(3-6 \mathrm{~mm})$ и алюминиевого сплава (7-12 mm).

Таким образом, разработана экспериментальная методика исследования высокоскоростного движения группы суперкавитирующих ударников в воде при одновременном старте из гладкоствольной баллистической установки. Разработаны ударники из высокопрочного сплава ВНЖ-95, которые при скорости $\sim 1100 \mathrm{~m} / \mathrm{s}$ движутся в воде в режиме суперкавитации. Показано, что два ударника на начальном участке траектории движения незначительно расходятся из-за взаимного влияния, в дальнейшем сохраняют поступательное движение по параллельным траекториям. Полученные результаты демонстрируют возможность устойчивого движения группы суперкавитирующих ударников в воде и достижения ими подводной цели. 


\section{Финансирование работы}

Исследование выполнено за счет гранта Российского научного фонда (проект № 19-19-00233).

\section{Конфликт интересов}

Авторы заявляют, что у них нет конфликта интересов.

\section{Список литературы}

[1] Логвинович Г.В. Некоторые вопросы глиссирования и кавитации. Тр. ЦАГИ. 1980. В. 2052. $271 \mathrm{c.}$

[2] Федоров С.В., Велданов В.А. // ЖТФ. 2013. Т. 83. В. 2. С. 15 20.

[3] Ибен У., Иванов Н.Г., Исаенко И.И., Шмидт А.А. // Письма в ЖТФ. 2015. Т. 41. В. 24. С. 1-8.

[4] Буркин В.В., Акиншин Р.Н., Афанасьева С.А., Борисенков И.Л., Ищенко А.Н., Хабибуллин М.В., Чупашев А.В., Югов Н.T. // Инж.-физ. журн. 2018. Т. 91. № 3. С. 701-708.

[5] Буркин В.В., Ищенко А.Н., Майстренко И.В., Фуфачев В.М., Дьячковский А.С., Бураков В.А., Корольков Л.В., Степанов Е.Ю., Рогаев К.С., Саммель А.Ю., Сидоров А.Д., Чупашев А.В. Гидробаллистический стенд. Патент 2683148 РФ. Опубл. 26.03.2019.

[6] Афанасьева С.А., Белов Н.Н., Бураков В.А., Буркин В.В., Зыков Е.Н., Ищенко А.Н., Родионов А.А., Симоненко В.Г., Хабибуллин М.В., Югов Н.Т. // Фундаментальная и прикладная гидрофизика. 2012. Т. 5. № 3. С. 43-55. 